\title{
Hospitalização Domiciliária em Portugal: um novo campo de actuação do Serviço Social hospitalar
}

\author{
Home Hospitalization in Portugal: a new field of action in the hospital's \\ Social Work
}

Fátima Marisol Gonçalves Ferreira ${ }^{1}$

\begin{abstract}
Resumo
O presente artigo pretende dar a conhecer práticas da intervenção do serviço social na Unidade de Hospitalização Domiciliária (UHD) do Centro Hospitalar Universitário de Lisboa Central (CHULC), assim como caracterizar os doentes tratados e respostas sociais activadas no âmbito do internamento domiciliário. Trata-se de um estudo de abordagem quantitativa, do tipo descritivo e exploratório. Entre Maio de 2019 e Maio de 2020, foram avaliados para admissão na UHD do CHULC, 232 doentes, dos quais 122 foram excluídos por diversos motivos e 110 doentes foram tratados. Dos doentes tratados em domicílio, 28 necessitaram da intervenção do assistente social. Os dados foram recolhidos através da análise dos processos sociais, obtidos pelos registos da actividade do assistente social nos sistemas informáticos SAAS (Sistema de Apoio ao Assistente Social) e SClínico e elaborada uma folha de registo específica para recolha dos seguintes parâmetros: o perfil do utente, motivos de exclusão, diagnóstico social e respostas sociais que foram accionadas. Os resultados desta análise permitem verificar que a intervenção do assistente social na UHD é insubstituível, fundamental e determinante no apoio ao doente e família e na qualidade da prestação dos serviços de saúde.
\end{abstract}

Palavras-chave: hospitalização domiciliária, serviço social, intervenção social.

\begin{abstract}
Summary
The present article intends to make known social service intervention practices in the Unidade de Hospitalização Domiciliária (Home Hospitalization Unit) (UHD) of the Centro Hospitalar Universitário de Lisboa Central (CHULC), as well as caracterize the treated patients and social responses within the framework of home hospitalization. This is a study of quantitative approach, of the descriptive and exploratory type. Between May of 2019 and May of 2020, 232 patients were evaluated for admission in the UHD of the CHULC, of which 122 were excluded for several reasons and 110 patients were treated. Of the treated patients in home hospitalization, 28 required the social worker's intervention. The data was collected through the analysis of the social processes, obtained by the records of the social worker's analysis in the computer programs "SAAS" (Sistema de Apoio ao Assistente Social) and "SClínico" and a specific record sheet was created in order to collect the following parameters: the patient's profile, reasons for exclusion, social diagnosis and the social responses that were put into action. The results of this analysis allow us to verify that the social worker's intervention in the UHD is irreplaceable, fundamental and determinant in the support for the patient and their family and in the quality of the health care.
\end{abstract}

Keywords: home hospitalization, social work, social intervention.

\footnotetext{
1 Assistente Social no Centro Hospitalar Universitário de Lisboa Central, EPE | E-mail:
} fatimamgf@hotmail.com 


\section{Introdução}

Actualmente, o aumento da esperança média de vida, para a qual têm contribuído as melhorias das condições de higiene e dos cuidados de saúde prestados, acompanha consequentemente o envelhecimento da população. Este envelhecimento populacional está associado ao aumento da prevalência de doenças crónicas, o que representa neste momento um problema transversal aos sistemas de saúde, levando a uma sobrelotação dos serviços de urgência/serviços de internamento hospitalares e a pressão cada vez maior por camas hospitalares (Delerue \& Correia, 2018). Como resposta, têm-se desenvolvido alternativas ao internamento convencional, onde se incluem as UHD.

A hospitalização domiciliária, enquanto modelo de prestação de cuidados de saúde em casa, afigura-se como uma alternativa ao internamento convencional, proporcionando assistência contínua e coordenada aos utentes que, requerendo admissão hospitalar para internamento, cumpram um conjunto de critérios clínicos, sociais e geográficos que permitem a sua hospitalização no domicílio, sob a responsabilidade dos profissionais de saúde que constituam uma UHD, com a concordância do cidadão e da família (Despacho 9323-A/2018 - DR). Esta modalidade de internamento confunde-se com o conceito conhecido de cuidados continuados no domicílio, a funcionar no contexto dos cuidados de saúde primários. A diferença dá-se sobretudo pelo facto das UHD darem resposta ao doente agudo e ao doente crónico agudizado, com patologias de elevada complexidade, mas com viabilidade de internamento no domicílio. O funcionamento destas unidades exige uma permanente interacção e cooperação de profissionais de várias disciplinas, onde estão incluídos os assistentes sociais, com a finalidade de definir para o doente um plano de cuidados holístico. Tratando-se de um novo campo de actuação do serviço social hospitalar urge uniformizar modelos e metodologias de intervenção. Com o presente artigo, pretende-se dar a conhecer práticas da intervenção do serviço social da UHD do CHULC, assim como caracterizar os doentes tratados e respostas sociais accionadas no âmbito do internamento domiciliário, tendo por base um estudo de cariz quantitativo, do tipo exploratório e descritivo.

\section{O surgimento das UHD - breve resenha histórica}

Esta modalidade de internamento surgiu pela primeira vez em 1947, nos Estados Unidos da América, com a experiência "Home Care”, organizada pelo Dr. Bluestone no Hospital Montefiore, em Nova Iorque, que visava descongestionar os hospitais, assim como criar um ambiente emocional e psicológico mais favorável ao doente. A primeira 
unidade a funcionar neste âmbito, chegou à Europa em 1957, no Assistance Publique Hôpitaux de Paris (AP-HP). Durante a década de 60, surgiram ainda unidades no Reino Unido, Alemanha, Suíça e Canadá (Cotta, Suárez-Varela, González, Cotta, \& Ricós, 2001). Em Espanha, a hospitalização domiciliária teve início em 1983, num programa piloto no Hospital Universitário Cruces, onde atualmente existe a SEHAD (Sociedad Española de Hospitalización a Domicilio). Segundo a Sociedad Vasca de Hospitalización a Domicilio (2018), em Espanha encontram-se registadas cerca 110 unidades. Em França, a Federação Nacional de Estabelecimentos de Hospitalização Domiciliaria (FNEHAD), tem 300 unidades registadas e realizou em 2010 cerca de 100000 internamentos (Delerue \& Correia, 2018).

Em Portugal, a primeira unidade de hospitalização domiciliária surgiu em 2015, no Hospital Garcia da Horta. Existem actualmente 32 unidades operacionais, de norte a sul do país o que significa, em termos práticos, um total de cerca de 300 camas de internamento (SPMI, 2021).

\section{Enquadramento funcional e organizacional das UHD's}

A UHD é constituída por uma equipa multidisciplinar composta por médico, enfermeiro, assistente social, farmacêutico, nutricionista e outros profissionais que sejam necessários para o bom funcionamento e eficácia da equipa no tratamento ao doente. Compete a UHD o acompanhamento do doente desde o momento da admissão, definindo em articulação com a equipa clínica hospitalar, que acompanhou o doente até a hospitalização domiciliária, um plano individual de cuidados. Estas equipas estão disponíveis 24 h por dia, 365 dias por ano, assegurando o esclarecimento de dúvidas e/ou resposta a agudização da situação clínica do doente. É sempre passível a transferência do doente para o internamento convencional em caso de alteração da sua situação clínica ou quando as condições sociais e/ou estruturais não assegurem a segurança necessária para o tratamento do doente em domicílio ou ainda quando o doente/família assim o desejam (Direcção Geral de Saúde, 2018).

O internamento em UHD exige que o doente preencha critérios clínicos, sociais e geográficos ${ }^{2}$ :

\footnotetext{
${ }^{2}$ Critérios definidos pela Direcção Geral de Saúde, com publicação na norma 020/2018 de 20/12/2018 https://www.dgs.pt/directrizes-da-dgs/normas-e-circulares-normativas/norma-n-0202018-de-20122018pdf.aspx
} 
- Clínicos: a situação clínica assume-se como transitória (doença aguda ou crónica agudizada), as comorbilidades têm de ser passíveis de serem controladas em contexto domiciliário e os diagnósticos clínicos, que requerendo internamento, têm de apresentar estabilidade clínica;

- Sociais: existência de cuidador com capacidade física, emocional e mental para assumir a vigilância permanente do doente (é facultativo no caso dos doentes autónomos), capacidade de manuseamento do doente e/ou cuidador de um meio de contacto (telemóvel/telefone), boas condições habitacionais e inexistência de barreiras linguísticas que impeçam o bom entendimento do plano de cuidados.

- Geográficos: o domicílio tem de estar na área de influência definida pela UHD.

A admissão na UHD exige a aceitação voluntária do doente/cuidador/representante legal com a assinatura de um consentimento informado, antes do início da hospitalização no seu domicílio.

São motivos de exclusão para internamento domiciliário, o incumprimento de qualquer motivo de inclusão e, ainda, a existência de comportamentos de dependência a substâncias ilícitas ou dependência alcoólica com consumos activos, doentes com patologias de foro psiquiátrico descompensadas e indigentes/pessoa sem abrigo.

O internamento do doente em qualquer UHD pressupõe o cumprimento de um circuito definido na norma $\mathrm{n}^{\circ}$ 020/2018 de 20/12/2018 e adaptado internamente por cada UHD, tendo em conta as suas especificidades.

Figura $\mathrm{n}^{\circ}$ 1: Circuito do doente na UHD

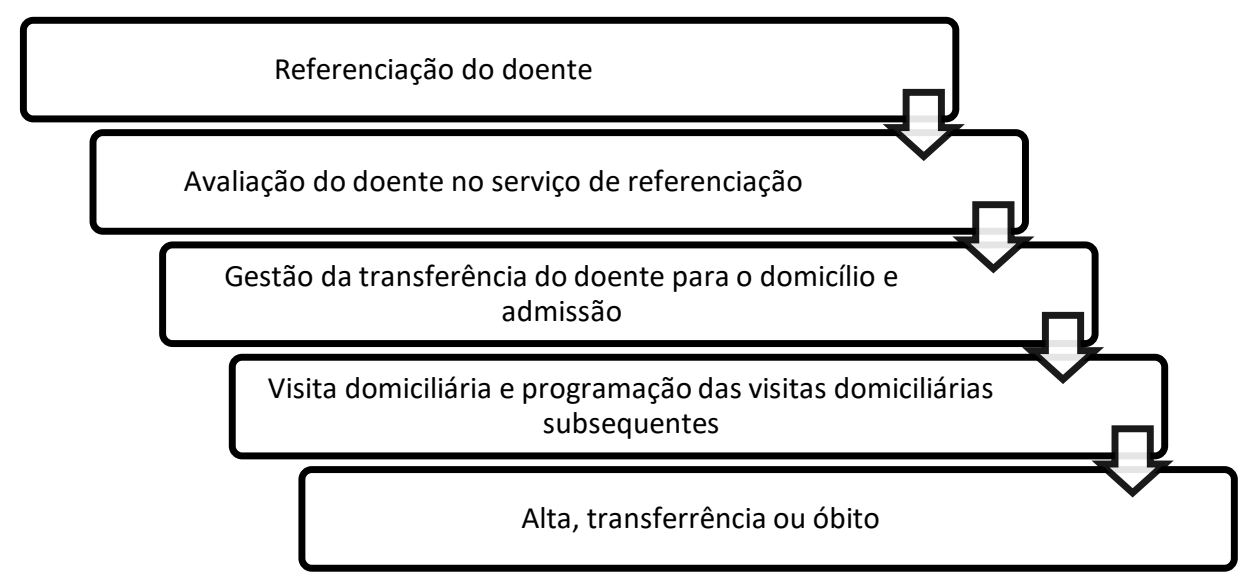

A figura 1 é elucidativa do circuito que o internamento domiciliário exige: a referenciação do doente pode ser realizada tendo por base dois modelos, um parte das referenciações das enfermarias médicas e cirúrgicas, dos serviços de urgência, consultas 
externas e hospital de dia e outro das referenciações realizadas directamente da comunidade, nomeadamente dos cuidados de saúde primários. Após a referenciação do doente que poderá ser elegível para internamento domiciliário, a equipa efectua presencialmente a avaliação do doente tendo por base os critérios de admissibilidade e exclusão definidos. Quando o doente é elegível para internamento em UHD e após assinatura do consentimento informado de forma voluntária, é iniciada a planificação e gestão da transferência do doente, incluindo articulações intrainstitucionais e interinstitucionais necessárias.

Relativamente às visitas domiciliárias, estas "são programadas em reunião clínica de acordo com as necessidades de cada doente: podem ser singulares (só enfermeiro ou só médico), interdisciplinares (médico e enfermeiro) ou multidisciplinares. A primeira visita domiciliária é realizada nas primeiras 24h após a admissão.” (Direcção Geral de Saúde, 2018, p.4). A equipa visita diariamente o doente, com o objectivo de garantir a prestação dos cuidados clínicos necessários e a eficácia do plano de tratamento proposto.

O fim de todo o processo assistencial termina com a alta clínica, transferência ou óbito do doente.

Este modelo de internamento assenta em cinco princípios básicos (Unidade de Hospitalização Domiciliária do Hospital Garcia de Orta, 2018):

1. Voluntariedade do doente/família;

2. Igualdade de direitos e deveres do doente (em nenhuma circunstância o doente poderá ser prejudicado por se encontrar internado no seu domicílio, o acesso a qualquer outra especialidade é sempre garantida)

3. Humanização dos serviços e valorização do papel da rede informal de cuidados;

4. Equivalência na prestação dos cuidados;

5. Rigor na admissão e no seguimento clínico do doente.

Segundo Delerue and Correia (2018) e Cunha et al (2017), a hospitalização domiciliária tem mostrado inúmeras vantagens em relação ao internamento convencional, entre as quais, uma menor taxa de infeção nosocomial, menor incidência de síndrome confusional agudo, menor risco de acamamento, menor risco de deterioração do estado funcional do doente e de desnutrição, menor risco de quedas, maior envolvimento do doente e cuidador no plano de cuidados e maior adesão à terapêutica.

\section{Posicionamento das UHD mediante a pandemia COVID-19}


Desde o surgimento dos primeiros casos de infecções por SARS-CoV-2, no fim do ano de 2019, até a declaração do estado de pandemia COVID-19 pela Organização Mundial de Saúde, em Março de 2020, os serviços de saúde nacionais foram obrigados a uma reorganização profunda, por forma a dar resposta a um aumento exponencial na procura de cuidados de saúde. O Núcleo de Estudos da Hospitalização Domiciliária (NEHospDom) da Sociedade Portuguesa de Medicina Interna (SPMI), de acordo com as recomendações da Organização Mundial de Saúde, elaborou um documento de consenso sobre o posicionamento que as UHD poderiam adoptar mediante o estado pandémico, documento esse publicado pela Direcção Geral de Saúde (DGS), a 23 de Março de 2020, através da norma 004/2020. Considera-se que a UHD pode ter um papel importante e preponderante na resposta a pandemia COVID-19, numa primeira fase, internando o maior número de doentes NÃO-COVID em contexto domiciliário com o objetivo de libertar o maior número de camas no internamento convencional, para doentes com necessidade de uma maior vigilância clínica. Este primeiro momento, pressupõe o reforço do número de camas e de recursos humanos nas UHD. Numa segunda fase, prevê-se que as UHD possam internar doentes com COVID-19 desde que seguindo as orientações elencadas na norma 004/2020: o doente tem de ter pelo menos 7 dias de internamento convencional, com estabilidade e evolução clínica favorável; a necessidade de oxigénio não deverá ultrapassar os $21 / \mathrm{min}$; deve reunir condições habitacionais para que seja possível o isolamento em casa e o cuidador deve reunir condições físicas, mentais e emocionais para a activa colaboração na prestação dos cuidados ao doente. Numa terceira e última fase, este documento prevê que a UHD possa admitir directamente doentes com diagnóstico confirmado ou com suspeita de infecção por SARS-CoV-2.

A UHD afigura-se como parte integrante no combate a esta pandemia no seio do Serviço Nacional de Saúde. A delineação de estratégias e mecanismos de intervenção no acompanhamento de doentes em contexto domiciliário não é estanque e encontra-se em constante evolução e adaptação (Núcleo de Estudos de Hospitalização Domiciliária da Sociedade Portuguesa de Medicina Interna, 2020).

\section{A intervenção do serviço social na UHD}

A história do serviço social na saúde está estreitamente relacionada com o percurso evolutivo do próprio serviço social. Desde 1905, em Massachussets General Hospital, em Boston, até aos nossos dias, a intervenção dos assistentes sociais nos hospitais tem 
ganho terreno no que toca a inequívoca importância e indispensabilidade, sobretudo pela centralidade que coloca na dimensão psicossocial do adoecer e do estar doente (Masfret, 2012). Desde 2002 que as funções dos assistentes sociais em todos os serviços e estabelecimentos dependentes do Ministério da Saúde, onde estão inseridos os hospitais, estão definidas legalmente (Circular Normativa $n^{\circ} 8$ do Departamento de Modernização e Recursos da Saúde do Ministério da Saúde, 16 de Maio de 2002). Nos hospitais, o assistente social está integrado nas diferentes equipas multidisciplinares de prestação de cuidados, em contexto de internamento e ambulatório. A norma 020/2018, da DGS determina que o assistente social é parte integrante da UHD “(...) a UHD deve ser composta por uma equipa multidisciplinar hospitalar constituída por médicos, enfermeiros, farmacêuticos, nutricionistas, assistentes sociais e pode incluir outros técnicos de apoio".

À semelhança dos momentos metodológicos identificados na intervenção do assistente social no âmbito hospitalar, na UHD o assistente social desenvolve a sua intervenção, essencialmente em quatro fases (Lopes et al, 2012):

Figura $^{\circ}$ 2: Momentos metodológicos da intervenção do assistente social em contexto hospitalar

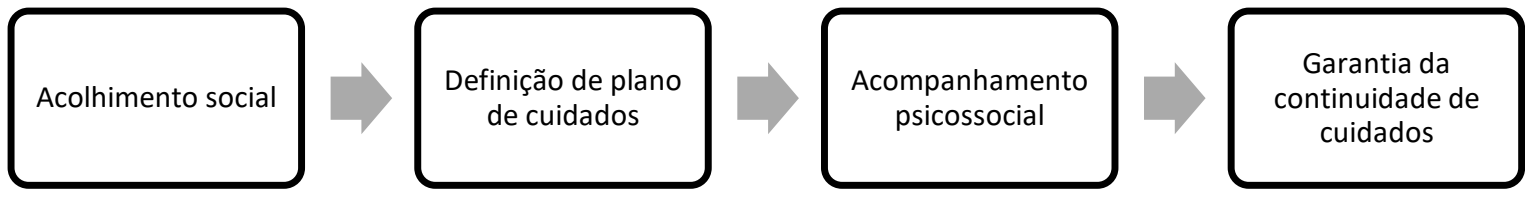

O acolhimento social é o primeiro contacto do assistente social com o doente/família candidato ao internamento domiciliário. Pressupõe uma entrevista de recolha de dados para a elaboração de um diagnóstico social (Lopes et al, 2012). No acolhimento social é realizada a validação dos critérios sociais obrigatórios de admissão na UHD, nomeadamente, a existência de cuidador permanente com capacidade física, mental e emocional para a prestação dos cuidados necessários, existência de rede de suporte formal, quando a situação assim o exige, alfabetismo e literacia, existência de condições habitacionais favoráveis ao internamento domiciliário (salubridade, higiene e conforto) e outros indicadores sociais que possam ser considerados imprescindíveis mediante a especificidade de cada situação, para o internamento na UHD. O resultado desta avaliação social é comunicado à restante equipa multidisciplinar para decisão conjunta da elegibilidade do doente ser internado na UHD. 
Numa lógica de constante articulação e cooperação de todos os profissionais, que esta modalidade de internamento exige, a elaboração do plano individual de cuidados é preparada no seio da equipa multidisciplinar, havendo partilha de informação de âmbito clínico e profissional para que sejam reunidas todas as condições necessárias para o sucesso do tratamento do doente no seu domicílio. O assistente social participa nas reuniões multidisciplinares da UHD, na periodicidade definida.

O acompanhamento psicossocial é prestado presencialmente ao doente e/ou cuidador sendo para isso necessário a realização de visitas domiciliárias. As visitas domiciliárias da UHD são realizadas em transporte próprio para o efeito e equipado para transportar pessoal médico, de enfermagem ou de apoio social com intuito de proporcionar tratamentos ao doente adulto nas respetivas casas. $\mathrm{O}$ assistente social da UHD realiza visitas domiciliárias por sua iniciativa ou por solicitação de qualquer profissional da equipa multidisciplinar que acompanha o doente. Ao assistente social compete efetuar o diagnóstico das necessidades de apoio social do doente no domicílio e /ou na comunidade, promovendo ações necessárias, para a sua satisfação com vista a proporcionar a continuidade de cuidados no pós-alta e, em determinadas situações, com vista ao internamento em UHD.

Podem ser realizadas dois tipos de visitas domiciliárias:

- Pré-hospitalização domiciliária- conhecer o espaço habitacional antes de se efetivar a transferência do doente. São realizadas nas situações em que, no momento do acolhimento social, surgem dúvidas relativamente às condições habitacionais favoráveis ao internamento domiciliário. No actual contexto pandémico, a avaliação habitacional assume uma importância primordial, na medida em que permite perceber se existem condições de isolamento para o doente com diagnóstico confirmado de COVID-19.

- Continuidade - manter uma vigilância permanente durante o período de internamento para o qual se constata que é necessário. Realizam-se sempre que se justifique.

Ao longo do internamento do doente na UHD, cabe ao assistente social orientar, encaminhar e articular com as instituições de apoio social da comunidade no sentido de garantir as condições necessárias para a continuidade de cuidados do doente após a alta, bem como informar os doentes/famílias sobre os seus direitos e prestações sociais. Compete ainda ao assistente social mediar as relações interpessoais entre o doente, 
equipa, família e redes formais de suporte social e promover e facilitar o estabelecimento de parcerias com projectos/entidades que facilitem a cura e recuperação do doente.

Nas situações em que o agregado familiar do doente é acompanhado por um técnico de alguma entidade/equipamento social da comunidade, compete ao assistente social da UHD, sempre que se justifique, prestar informações sobre a(s) visita(s) efetuada(s), as condições actuais do domicílio e o levantamento das necessidades encontradas.

O acompanhamento psicossocial pressupõe que o assistente social avalie a situação do doente/família numa perspectiva de alta e de continuidade dos cuidados, através da identificação das necessidades e mobilização dos recursos para a prestação dos cuidados necessários, tendo em conta a sua doença e dependência (Lopes et al, 2012).

A garantia da continuidade de cuidados prende-se com a identificação, em conjunto com o doente e equipa multidisciplinar, das necessidades que resultaram da situação de doença e que poderão motivar um conjunto de constrangimentos na fase de recuperação e reintegração do doente na comunidade. Nesta fase, o assistente social deve validar junto do doente/família a existência dos recursos necessários à alta, articular com os parceiros sociais no sentido de garantir a prestação dos serviços/respostas sociais reconhecidos como imprescindiveis à continuidade dos cuidados e garantir o entendimento do doente/cuidador do plano de cuidados definido (Lopes et al, 2012). A preparação da alta e a garantia da continuidade dos cuidados deve ser iniciada o mais precocemente possível, de forma integrada e multidisciplinar, com o objetivo final de proporcionar ao doente uma alta segura, estruturada e atempada.

\section{Metodologia}

Trata-se de um estudo de abordagem quantitativa, do tipo descritivo e exploratório, com o objectivo de:

1. caracterizar o perfil dos doentes que necessitaram da intervenção do serviço social durante o período de internamento na UHD do CHULC;

2. identificar os principais critérios de exclusão;

3. identificar os principais diagnósticos sociais;

4. caracterizar as condições habitacionais;

5. elencar as respostas sociais que foram accionadas.

A amostra foi constituída por 232 doentes, dos quais 122 foram excluídos por diversos motivos e 110 doentes foram tratados, representando 47,4\% dos doentes 
sinalizados. A UHD do CHULC dispõe de 5 camas de internamento e iniciou a sua actividade assistencial em Maio de 2019.

Os dados foram recolhidos através da análise dos processos sociais e elaborada uma folha de registo específica para recolha dos seguintes parâmetros: motivos de exclusão, o perfil do utente, condições habitacionais, diagnóstico social e respostas sociais accionadas no âmbito do internamento em UHD. Os dados foram obtidos através da consulta dos processos sociais nos sistemas informáticos de registo da actividade do assistente social. Os dados relativos ao período de Maio de 2019 até Dezembro de 2019, foram consultados no SAAS, os restantes, do período de Janeiro a Maio de 2020, no SClinico. De referir que a necessidade de consulta nos dois sistemas informáticos deveu-se ao facto de ter existido no início do ano de 2020 a introdução do perfil do assistente social no sistema informático SClínico, exigindo a mudança de sistema operacional de registos no âmbito da actividade do serviço social hospitalar. O acesso e análise aos processos sociais dos doentes implicou uma autorização expressa por parte da Comissão de Ética para a Saúde (CES) do CHULC.

Relativamente, a avaliação do parâmetro "condições habitacionais" teve por base o documento "Critérios de admissão do doente na UHD CHULC" elaborado internamente pela equipa da UHD do CHULC.

O presente estudo, do ponto de vista dos objetivos, assume-se como um estudo descritivo e exploratório pois pretende descrever, identificar e elencar a intervenção do assistente social no seio das equipas multidisciplinares das UHD, permitindo reflectir em torno do papel insubstituível e fundamental deste profissional no apoio ao doente/família.

\section{Resultados}

Considerando a análise dos doentes que foram sinalizados a UHD do CHULC entre Maio de 2019 e Maio de 2020, identificou-se um total de 232 doentes, dos quais 122 doentes foram excluídos pela inelegibilidade de critérios, 110 doentes foram admitidos e tratados na UHD. 28 dos doentes internados foram alvo da intervenção do assistente social ( $25 \%$ dos doentes tratados).

\section{Principais motivos de exclusão para internamento na UHD}

Os motivos de exclusão de um doente para admissão em UHD, podem assumir várias dimensões, sendo que no período analisado, no CHULC, o principal motivo de exclusão deveu-se a questões clínicas, sobretudo relacionadas com a falta de diagnóstico e plano terapêutico estabelecido com certeza e ausência de estabilidade clínica e comorbilidades não controláveis no domicílio (gráfico $\mathrm{n}^{\mathrm{o}} 1$ ). 
Gráfico $\mathrm{n}^{\circ} 1$. Motivos de exclusão para internamento na UHD

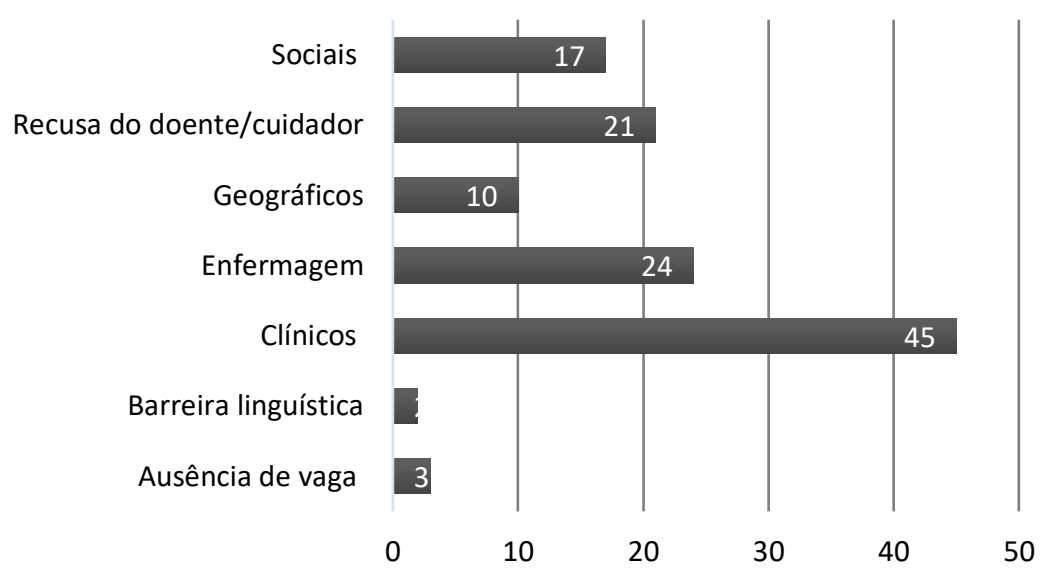

Foram excluídos desta tipologia de internamento, 24 doentes por critérios de enfermagem, essencialmente relacionados com a inviabilidade de acesso venoso do doente. De referir que 21 doentes, foram excluídos por recusa dos mesmos ou do cuidador.

Relativamente aos motivos sociais de exclusão, conclui-se, conforme gráfico número 2, que dos 17 doentes excluídos, 94\% deveu-se a ausência de cuidador/suporte social e $6 \%$ à incapacidade do cuidador.

Gráfico $n^{\circ} 2$. Motivos sociais de exclusão para internamento em UHD

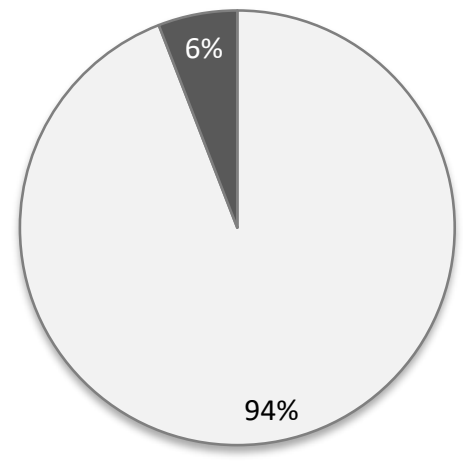

$\square$ Ausência de cuidador/suporte social $\quad$ Incapacidade do cuidador

A maioria dos utentes que recorrem aos serviços de saúde hospitalares são idosos, com estados funcionais incapacitantes, várias comorbilidades associadas e, naturalmente com necessidade de apoio permanente em contexto domiciliário, seja através da rede de suporte informal (família, vizinhos, amigos) ou formal (instituições de apoio social). A inexistência deste suporte social inviabiliza o tratamento do doente no seu domicílio. $\mathrm{O}$ 
tempo de agilização do encaminhamento para um apoio social e o início efectivo desse apoio é, muitas vezes, incompatível com os tempos hospitalares. Nos casos em que existe um cuidador informal, na maioria das vezes também idoso, a ausência de condições físicas, emocionais e mentais para a prestação dos cuidados necessários à pessoa doente impossibilita igualmente a concretização desta tipologia de internamento.

\section{O perfil do doente acompanhado pelo serviço social no âmbito da UHD}

Entre Maio de 2019 e Maio de 2020, foram acompanhados pelo serviço social em regime de hospitalização domiciliária 28 doentes. Tendo em conta o género desses doentes, verificou-se que o número de doentes do género masculino foi superior (15) aos do género feminino (13).

Relativamente a idade destes doentes denota-se uma grande incidência nas faixas etárias mais avançadas, dos 80 aos 89 anos, concluindo que a maioria das situações acompanhadas pelo Serviço Social recai sobre os doentes idosos e os muito idosos (> de 90 anos), num total de 13 doentes (Gráfico $n^{\circ}$ 3). A necessidade da intervenção social nestes grupos etários é explicada através da concepção do próprio processo de envelhecimento biológico que se traduz num conjunto de transformações que levam a um declínio significativo da capacidade funcional da pessoa e que exige, por parte das equipas de saúde, uma intervenção integrada e holística, dando especial ênfase a dimensão social do doente.

Gráfico $\mathrm{n}^{\circ} 3$. Número de doentes por grupo etário

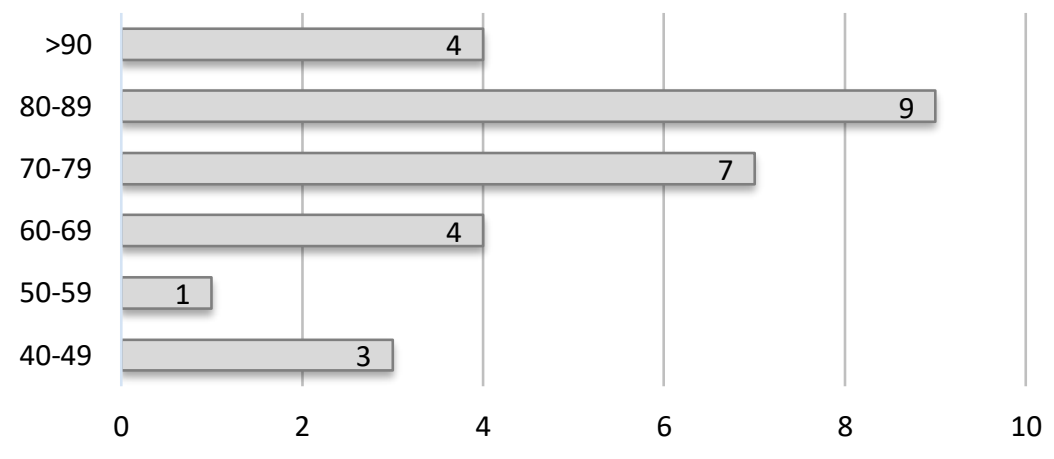

Verificou-se que a maioria dos doentes acompanhados, durante este período, eram maioritariamente casados (75\%), 18\% eram viúvos e apenas $7 \%$ solteiros.

Dos doentes em análise constatou-se que $86 \%$ dos mesmos estavam em situação de reformados e pensionistas e 14\% em situação de emprego activo (Gráfico nº 4).

Gráfico $n^{\circ} 4$. Número de doentes por situação profissional 


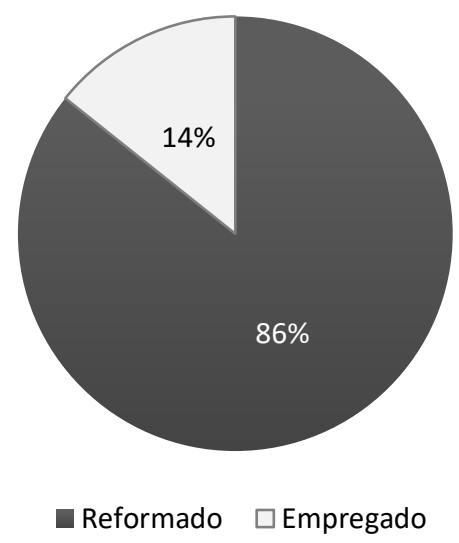

No que concerne a constituição do agregado familiar, concluiu-se que 21 dos doentes em análise residiam com o seu cônjuge, 3 com filhos, 2 com cuidador formal, 1 com outros familiares e 1 sozinho (Gráfico $\mathrm{n}^{\circ}$ 5). O internamento em unidade de hospitalização permite que o doente resida só, desde que reúna condições físicas, mentais e emocionais para o autocuidado necessário. A maioria dos doentes tratados e acompanhados pelo serviço social residiam com os seus cônjuges, que à semelhança dos mesmos, apresentavam idades avançadas, constituindo-se a maioria como os principais cuidadores dos doentes.

Gráfico nº 5. Composição do agregado familiar

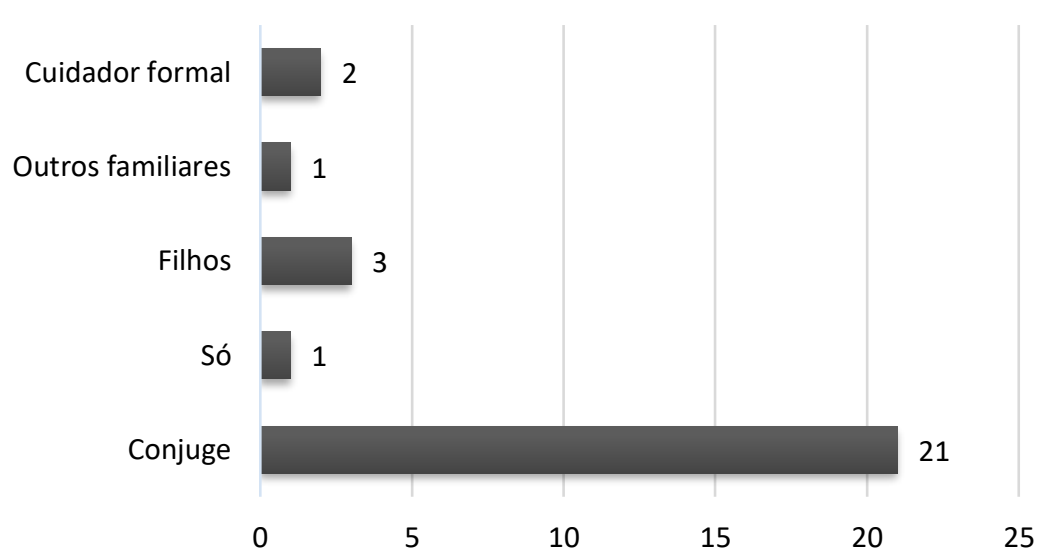

Relativamente à funcionalidade dos doentes, $43 \%$ dos doentes que foram alvo da intervenção do serviço social encontravam-se numa situação de dependência física e mental, que implica a presença permanente de cuidados. 39\% destes doentes encontravam-se numa situação de semidependência. A população idosa apresenta, maioritariamente, múltiplas patologias e doenças crónicas associadas e, consequentemente, maior dependentes, acabando por serem os doentes com maior 
necessidade de apoio social, no que toca aos encaminhamentos para serviços de prestação de apoio, nomeadamente, apoios domiciliários e encaminhamentos para a rede nacional de cuidados continuados integrados. e $18 \%$ de autonomia total (Gráfico $\mathrm{n}^{\circ}$ 6).

Gráfico $n^{\circ}$ 6: Funcionalidade do doente

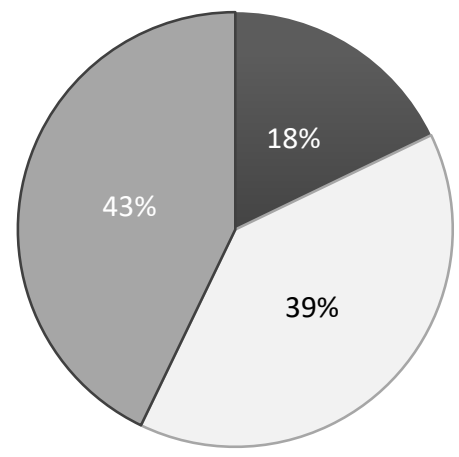

$\square$ Independente $\square$ Semi-dependente $\square$ Dependente

\section{Realidade habitacional dos doentes acompanhados na UHD do CHULC}

A hospitalização domiciliária implica visitas diárias da equipa ao domicílio do doente. Estas visitas podem ser individuais, interdisciplinares e multidisciplinares. Da análise dos dados recolhidos, o assistente social realizou 29 visitas domiciliárias, 28 delas de continuidade e 1 de pré internamento do doente. A área de abrangência da UHD do CHULC é maioritariamente constituída pelas freguesias centrais da cidade de Lisboa, caracterizadas maioritariamente por prédios de fachadas antigas e degradadas, com divisões exíguas, prédios sem elevadores e com difíceis acessos. Da análise realizada concluiu-se que a maioria das habitações, apesar de antigas, encontravam-se em bom e razoável estado geral de conservação (Gráfico $\mathrm{n}^{\circ}$ 7).

Gráfico $n^{\circ} 7$. Estado geral de conservação da habitação

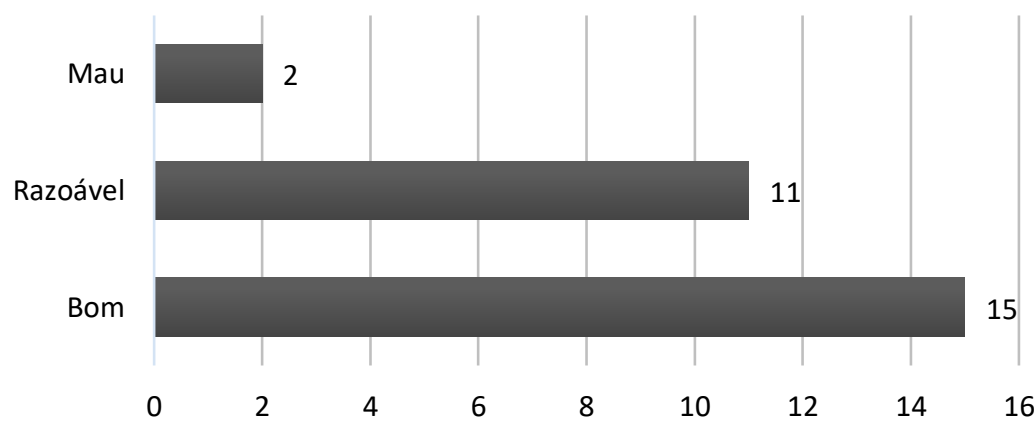

Destacam-se duas situações em que as habitações apresentavam mau estado geral, sobretudo relacionado com a falta de higiene e desorganização no interior da mesma. 
Nestas situações a intervenção do assistente social incidiu na sensibilização para a higiene da habitação com referência a alguns projectos sociais existentes neste âmbito.

Relativamente às barreiras arquitetónicas no acesso e no interior das habitações verificou-se que a maioria não apresentava qualquer barreira arquitectónica que condicionasse a mobilidade do doente e $29 \%$ das habitações apresentavam barreiras que dificultavam o dia a dia do doente, sobretudo, degraus tanto no acesso como no interior. (Gráfico $\left.n^{\circ} 8\right)$.

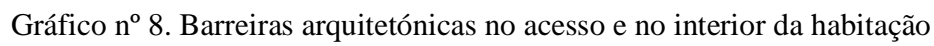

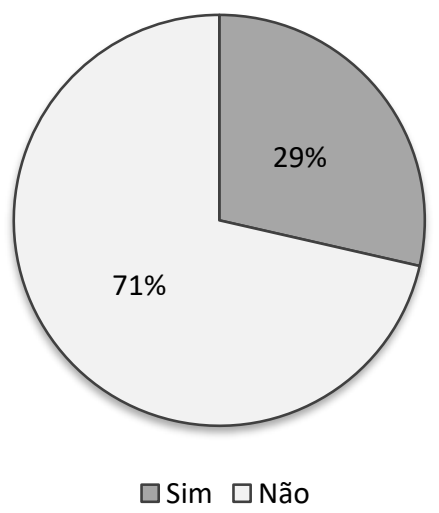

\section{Diagnósticos Sociais identificados e respostas accionadas}

A intervenção do assistente social pressupõe a definição de um diagnóstico social. Segundo Guerra (2002), o diagnóstico social é o instrumento primordial na definição de um bom plano de intervenção social, possibilita-nos compreender as causas dos problemas, permite perceber a realidade e interpretá-la, identificar as vulnerabilidades, as ameaças, as oportunidades e as potencialidades do individuo. Dos dados recolhidos a intervenção do assistente social no seio destes agregados permitiu identificar como principais diagnósticos sociais os seguintes:

- Dificuldades de natureza económica

- Dificuldades de natureza habitacional

- Dificuldade de cumprimento do plano terapêutico / alta

- Limitações da funcionalidade individual / familiar por presença de incapacidade ou doença

- Necessidades de informação / orientação para acesso a direitos sociais ou de saúde

- Perturbação nas relações familiares / relações significativas

- Recursos e meios de apoio 
- Sinais de comportamento ou contexto de risco social

Tendo por base os diagnósticos sociais identificados foram realizados 6 encaminhamentos para serviço de apoio domiciliário, 10 encaminhamentos para pedidos de benefícios sociais, sobretudo relacionados com complementos às pensões/reformas, 2 encaminhamentos para a contratação de cuidador formal, 1 encaminhamento para centro dia e 9 situações que exigiram a activação de respostas mais especificas, relacionadas com a imigração, regularização de documentos de identificação, higienização dos domicílios, banco alimentar, banco de roupa e ajudas técnicas (Gráfico nº 9).

Gráfico $\mathrm{n}^{\circ}$ 9: Respostas sociais accionadas

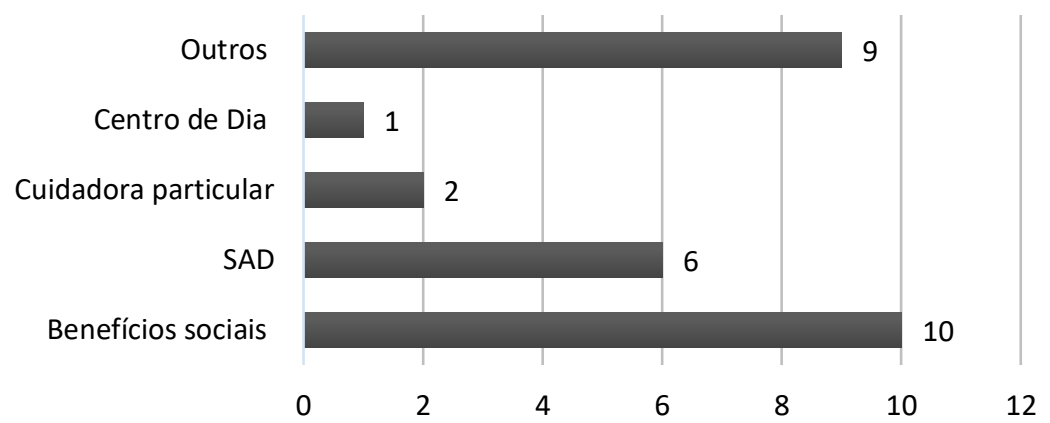

No âmbito da intervenção do serviço social na UHD, durante o período em análise foram ainda realizadas 5 referenciações à RNCCI, 2 para tipologia de Média Duração e de Reabilitação, 2 para as Equipas de Cuidados Continuados Integrados e 1, em colaboração com a Equipa Intrahospitalar de Suporte aos Cuidados Paliativos do CHULC, para tipologia de Cuidados Paliativos.

\section{Discussão e conclusão}

Tendo por base o já elevado número de estudos realizados no âmbito da actividade das $\mathrm{UHD}^{3}$, a nível nacional e internacional, e tendo em conta o caráter inovador desta tipologia de internamento, é possível elencar um conjunto de vantagens inerentes a hospitalização domiciliária, tais como:

\footnotetext{
${ }^{3}$ Estudos no âmbito da intervenção da UHD https://aua.pt/wp-content/uploads/2021/03/Inque\%CC\%81rito-sobre-Hospitalizac\%CC\%A7a\%CC\%83oDomicilia\%CC\%81ria-v01.pdf https://comum.rcaap.pt/bitstream/10400.26/35312/1/Disserta\%C3\%A7\%C3\%A3o\%20de\%20mestrado_I n\%C3\%AAs\%20Melo.pdf https://www.ncbi.nlm.nih.gov/pubmed/29364795 http://scielo.iec.gov.br/pdf/rpsp/v10n1/5850.pdf
} 
- redução dos custos de internamento;

- libertação de camas hospitalares;

- diminuição do número de dias de internamento;

- redução de infeções hospitalares;

- tratamento mais individualizado e mais próximo;

- maior eficiência na transmissão de informação ao doente e à família;

- uma maior articulação e comunicação entre os serviços hospitalares e os cuidados de saúde primários;

- redução do número de readmissões hospitalares;

- humanização dos serviços de saúde;

- internamento mais cómodo e mais seguro para o doente;

- melhoraria da satisfação de doentes e familiares.

Este modelo de internamento proporciona ao doente cuidados individualizados e com presumivelmente menores custos associados. A aceitação desta modalidade de internamento e a evidência das vantagens listadas, leva-nos a clara necessidade de incentivo e aposta no crescimento e desenvolvimento do internamento domiciliário em Portugal.

Através da análise dos dados que foram apresentados, o doente internado na UHD do CHULC assume o seguinte perfil: homem, com idade compreendida entre os 80 e os 89 anos, reformado, a residir com cônjuge e dependente mental e fisicamente. Do ponto de vista habitacional assume-se que a maioria dos domicílios se encontram em bom estado de conservação e não apresentam barreiras arquitetónicas no exterior e interior. Relativamente aos doentes que não foram admitidos nesta modalidade de internamento, ficou a dever-se sobretudo a razões clínicas. Os factores sociais de exclusão prenderamse com a ausência de cuidador/rede social de suporte. No que diz respeito às respostas sociais accionadas no âmbito da intervenção do assistente social na UHD foram sobretudo relacionadas com benefícios sociais incidindo, desta forma, na garantia dos direitos do doente. As respostas sociais específicas e multidimensionais activadas, são o reflexo da versatilidade que a intervenção do assistente social exige neste campo.

No que concerne à intervenção do serviço social nas UHD, a experiência ainda curta da UHD do CHULC, apresenta números pequenos para que possa haver uma casuística com relevância significativa. Contudo, podemos concluir que o assistente social é um elemento necessário e insubstituível no seio destas equipas, na medida em que a sua 
intervenção proporciona ao doente/ família um conjunto de condições físicas, emocionais e logísticas que permitem o tratamento deste em contexto domiciliário, com as devidas condições de segurança e qualidade diferenciadas e, permite ainda, a garantia da continuidade de cuidados do doente após a alta, seja em meio domiciliário ou institucional. A intervenção do serviço social nas UHD, à semelhança do que acontece nos internamentos convencionais, segue uma metodologia própria que implica a avaliação das necessidades e das condições médico-sociais do doente/família, a definição de um plano de cuidados, o acompanhamento psicossocial ao doente/família e a garantia da continuidade de cuidados, com a grande vantagem de realizar a sua intervenção in loco.

A visita domiciliária é um instrumento técnico-metodológico, privilegiado pelo assistente social neste modelo de hospitalização. Permite avaliar as condições da habitação e facilita a aproximação do profissional à realidade do doente e família. O carácter informal que este modelo de internamento impõe, permite que o doente e família exponha com maior facilidade os seus problemas e o assistente social de forma mais eficaz e pragmática, efectue os encaminhamentos adequados à situação.

No concernente a humanização dos serviços de saúde é inequivocamente atribuída ao assistente social um papel preponderante, na medida em que é o profissional que lida com as vertentes mais subjectivas do ser humano.

O serviço social hospitalar detém especificidades e assume uma complexidade singular que viabiliza a constante e, já antiga preocupação na uniformização e normalização dos modelos e dos cuidados prestados. A intervenção do serviço social nas UHD é recente e ainda se debate com problemas de identidade, sobretudo relacionados com práticas díspares dos profissionais. Os principais objectivos a curto prazo são a partilha, inovação e compilação de propostas de uniformização de práticas do assistente social no âmbito das UHD, a nível nacional.

\section{Referências bibliográficas}

Alves, M., Bigotte, M., Costa, J., \& Vaz-Carneiro, A. (2017). Analysis of the Cochrane Review: Early Discharge Hospital at Home. Acta Med Port, 30 (12), 835-839. https://www.ncbi.nlm.nih.gov/pubmed/29364795

Angelini University Award. (2019). Inquérito sobre Hospitalização Domiciliária. https://aua.pt/wp-content/uploads/2021/03/Inque\%CC\%81rito-sobre Hospitalizac\%CC\%A7a\%CC\%83o-Domicilia\%CC\%81ria-v01.pdf 
Cotta, R., Suárez-Varela, M., González, A., Filho, J., Real, E., \& Ricós, J. (2001). La hospitalización domiciliaria: antecedentes, situación actual y perspectivas. Rev Panam Salud PublicalPan Am J Public Health, 10 (1), 45-55. http://scielo.iec.gov.br/pdf/rpsp/v10n1/5850.pdf

Cunha V., Escarigo MC., Correia J., Nortadas R., Azevedo PC., Beirão P., Gomes A. \& Delerue F. (2017). Hospitalização domiciliária: Balanço de um ano da primeira unidade portuguesa. Revista da Sociedade Portuguesa de Medicina Interna, 24 (4), 290295. https://doi.org/10.24950/rspmi/O112/17/2017

Delerue F, Correia J. (2018). Hospitalização domiciliária mais um desafio para a medicina interna. Revista da Sociedade Portuguesa de Medicina Interna, 25 (1), 1517. https://doi.org/10.24950/rspmi/Op/1/2018

Despacho n. ${ }^{\circ}$ 9323-A/2018 de 3 de Outubro do Gabinete da Secretária de Estado da Saúde. (2018). Diário da República: II série, $\mathrm{n}^{\circ} 191$. https://dre.pt/application/file/a/116588707

DGS, Direção-Geral da Saúde. (2018). Hospitalização Domiciliária em idade adulta. Norma n. ${ }^{\circ}$ 020/2018 de 20/12/2018. 1-22. https://www.dgs.pt/directrizes-dadgs/normas-e-circulares-normativas/norma-n-0202018-de-20122018-pdf.aspx

DGS, Direção-Geral da Saúde. (2020). Abordagem ao doente com Suspeita ou Confirmação de COVID-19. Norma n. ${ }^{\circ}$ 004/2020 de 23/03/2020. 1-28. https://www.dgs.pt/normas-orientacoes-e-informacoes/normas-e-circularesnormativas/norma-n-0042020-de-23032020-atualizada-a-141020201.aspx

DMR, Departamento de Modernização e Recursos da Saúde. Circular normativa $n$. 8, de 16 maio de 2002. https://servicosocialsaude.files.wordpress.com/2008/03/mscircular-normativa-n-8-16-maio-2002.pdf

Guerra, I. (2002). Fundamentos e processos de uma sociologia de acção - $O$ planeamento em ciências sociais. Principia.

Lopes, M., Ribeiro, A., Santo, I., Ferreira, F. \& Frederico, L. (2012). Serviço social e qualidade em contexto hospitalar. In Carvalho, M. (Ed.), Serviço social na saúde (pp.2552). Pactor.

Masfret, D. (2012). O Serviço Social de Saúde e o Planeamento da Alta para a Continuidade de Cuidados na Comunidade. In Carvalho, M. (Ed.), Serviço social na saúde (pp.55-80). Pactor.

Melo, M. (2020). Hospitalização domiciliária vs. hospitalização clássica, o modelo custo-efetivo: revisão sistemática da literatura [Master's thesis, Escola Superior de $\begin{array}{llll}\text { Enfermagem do Porto]. } & \text { Repositório } & \text { Comum }\end{array}$ RCAAP.https://comum.rcaap.pt/bitstream/10400.26/35312/1/Disserta\%C3\%A7\%C3A3 o\%20de\%20mestrado_In\%C3\%AAs\%20Melo.pdf

Núcleo de Estudos de Hospitalização Domiciliária da Sociedade Portuguesa de Medicina Interna. (2020). Documento de consenso de peritos sobre o posicionamento da hospitalização domiciliária como estratégia integrada no plano nacional de preparação e resposta para a doença por coronavírus (COVID-19).https://www.spmi.pt/wpcontent/uploads/2019/06/Documento-de-Consenso-Hospitalizac\%CC\%A7a\%CC\%83oDomicilia\%CC\%81ria-Plano-Contige\%CC\%82ncia-COVID19-.pdf

Sociedad Vasca de Hospitalización a Domicilio. (2018). Sobre SVHAD. Historia. https://www.svhad.net/sobre-svhd/\#historia 
Sociedade Portuguesa de Medicina Interna. (2021). Núcleo de Estudos de Hospitalização Domiciliária da Sociedade Portuguesa de Medicina Interna. História. https://www.spmi.pt/nucleo-de-estudos-de-hospitalizacao-domiciliaria/

Unidade de Hospitalização Domiciliária do Hospital Garcia de Orta. (2018). Programa funcional 2018 da unidade de hospitalização domiciliária do Hospital Garcia de Orta. http://www.hgo.pt/Portals/0/Docu-mentos/UHD_Plano_Funcional_2018.pdf 